\title{
Low bone density and osteoporosis among older adults with Alzheimer's disease, vascular dementia, and mixed dementia: A Cross-sectional Study With Prospective Enrollment
}

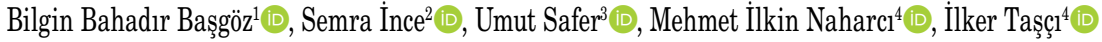 \\ ${ }^{1}$ Department of Internal Medicine, University of Health Sciences, Gülhane School of Medicine, Ankara, Turkey \\ ${ }^{2}$ Department of Nuclear Medicine, University of Health Sciences, Gülhane School of Medicine, Ankara, Turkey \\ ${ }^{3}$ Department of Geriatrics, University of Health Sciences, Sultan Abdulhamid Han Training and Research Hospital, Istanbul, Turkey \\ ${ }^{4}$ Department of Geriatrics, University of Health Sciences, Gülhane School of Medicine, Ankara, Turkey
}

Received: October 22, 2018 Accepted: February 27, 2019 Published online: May 18, 2020

\begin{abstract}
Objectives: This study aims to examine bone mineral density (BMD) and osteoporosis in older adults with dementia compared to those with a normal cognitive status and to evaluate the type, severity, and duration of dementia.

Patients and methods: Between May 2013 and May 2017, a total of 363 participants aged $\geq 65$ years (136 males, 227 females; mean age 78.4 5.4 years; range 66 to 99 years) with and without Alzheimer's disease (AD), vascular dementia (VaD), or mixed dementia $(\mathrm{AD}-\mathrm{VaD})$ were included in this single-center, prospective, cross-sectional study. The dementia group included 93 patients with dementia and the control group included 270 age- and sex-matched healthy individuals. We used dual-energy X-ray absorptiometry (DXA) to measure BMD of the lumbar spine, total hip, and femoral neck.

Results: Controlled for age and sex, demented and non-demented participants had a similar BMD (g/cm²) at lumbar spine [F (1, 358):0.83, $\mathrm{p}=363]$, but lower BMD values of total hip [F (1,359):10.26, $\mathrm{p}=0.001]$ and femoral neck [F $(1,359): 15.21$, $\mathrm{p}<0.001]$ in the patients with dementia. Adjusted percentage of osteoporosis and low bone mass based on total hip and femoral neck T-scores were also significantly higher in the patient group. The mean BMD values, frequency of osteoporosis, and low bone mass did not significantly differ according to the subtype of dementia, sex, and disease duration or severity.

Conclusion: Our study results show that demented elders have a lower BMD and higher frequency of osteoporosis at the hip, but not at the lumbar spine, irrespective of sex and type of dementia. Based on these results, we can speculate that not only AD, but also VaD and AD-VaD may be associated with bone loss at the hip.
\end{abstract}

Keywords: Alzheimer's disease, bone disease, metabolic, vascular, osteoporosis.

Osteoporosis is more frequent than many chronic conditions of older age, and fragility fractures are among the common causes of morbidity and mortality in elderly individuals. ${ }^{[1]}$ A recent analysis in the United States has shown a $5.1 \%$ prevalence of osteoporosis in individuals aged 50 to 59 years, but has risen to $8 \%$, $16.4 \%$, and $26.2 \%$ over the next decades. ${ }^{[2]}$ It has been also reported that at least $40 \%$ in any age category have a low bone mass (LBM). ${ }^{[2]}$

Dementia is one of the leading etiologies which cause falls due to impairments in cognition, gait, and postural control. ${ }^{[3]}$ One-year incidence of falls among patients with dementia may reach up to 50 to $80 \%{ }^{[4]}$ Patients with dementia have a higher risk for fractures than non-demented individuals. ${ }^{[5]}$ Although osteoporosis is the primary predictor of fragility fractures, ${ }^{[1]}$ a pathophysiological link between dementia and osteoporosis is still unclear. Dementia and osteoporosis exhibit similarities such as earlier onset in women, association with depression, and the protective role of being overweight. ${ }^{[6-10]}$ On the other hand, in contrast to earlier findings, BMD loss and the

Corresponding author: Bilgin Bahadır Başgöz, MD. SBÜ Gülhane Ĕ̛itim ve Araştırma Hastanesi, İ̧ Hastalıkları Kliniği, 06018 Etlik, Ankara, Türkiye. e-mail: bbbasgoz@gmail.com 
diagnosis of osteoporosis are more common in patients with dementia. ${ }^{[11-13]}$ Moreover, recent meta-analyses have demonstrated that osteoporosis and lower femoral neck BMD increase the risk for developing Alzheimer's disease $(A D)$, while patients with $A D$ are at a higher risk for osteoporosis. ${ }^{[14]}$

Cardiovascular disease (CVD) increases the risk for developing not only dementia, but also osteoporosis and fractures in the general population. ${ }^{[15-18]}$ In the present study, we hypothesized that, patients with vascular dementia $(\mathrm{VaD})$ and mixed-type dementia $(\mathrm{AD}-\mathrm{VaD})$ could be at an increased risk for bone loss, compared to patients with AD. Therefore, we aimed to investigate the characteristics and variations in bone density at different sites, and the frequency of osteoporosis in elderly patients with three common forms of dementia.

\section{PATIENTS AND METHODS}

This single-center, prospective, cross-sectional study was conducted at Gülhane Training and Research Hospital, geriatric outpatient clinic between May 2013 and May 2017. A total of 363 participants aged $\geq 65$ years (136 males, 227 females; mean age $78.4 \pm 5.4$ years; range, 66 to 99 years) with and without $\mathrm{AD}, \mathrm{VaD}$, or $\mathrm{AD}-\mathrm{VaD}$ were included. We excluded those diagnosed with other types of dementia including frontotemporal dementia, Parkinson's dementia, and dementia with Lewy bodies. Other exclusion criteria were mild cognitive impairment (MCI), delirium or extreme neuropsychiatric behavior, current hospitalization, recent major surgery, or bilateral hip replacement surgery. As part of a survey focused on the association between CVD and geriatric comorbidities, the present data were collected from a geriatric outpatient clinic in the tertiary setting. All individuals underwent a comprehensive geriatric assessment, regardless of the presence of serious illnesses. The physician carefully recorded newly recognized or previously known comorbidities including osteoporosis with the help of the patients' spouse, family members, or caregivers. Eligible participants underwent dual-energy X-ray absorptiometry (DXA) measurement of the lumbar spine, total hip, and femoral neck regions during geriatric outpatient registry. A routine patient care also covered ordering a repeated BMD measurement, where indicated ${ }^{[19]}$ Individuals with no difficulty in activities of daily living, but with memory impairment and lower scores on the Mini-Mental State Examination (MMSE) (scores between 19 and 23 out of 30) were classified as having MCI. ${ }^{[20,21]}$ The dementia group included 93 patients with dementia and the control group included 270 age- and sex-matched healthy individuals with intact cognitive functions based on neuropsychological evaluation. ${ }^{[20]}$

A written informed consent was obtained from each participant. The study protocol was approved by the Keçiören Training and Research Hospital Ethics Committee (2012-KAEK-15/1256-2017). The study was conducted in accordance with the principles of the Declaration of Helsinki.

\section{Study protocol}

At study entry, we collected overall participant characteristics such as age, sex, education status, smoking, and comorbidities including coronary heart disease, stroke, diabetes mellitus, hypertension, and hypercholesterolemia. Anemia, hypothyroidism, vitamin B12 deficiency, folate deficiency, and vitamin $\mathrm{D}$ deficiency were diagnosed using the laboratory data obtained during the enrollment visit. We recorded the drugs in fixed-dose combination pills as separate medications and defined polypharmacy as the combined use of $\geq 5$ drugs.

The Diagnostic and Statistical Manual of Mental Disorders, Fifth Edition (DSM-V) was used in the diagnosis of dementia. ${ }^{[22]}$ Alzheimer's disease was diagnosed according to the criteria of National Institute of Neurological and Communicative Disorders and Stroke and the Alzheimer's Disease and Related Disorders Association. ${ }^{[23]}$ In addition, the National Institute of Neurological Disorders and Stroke-Association Internationale pour la Recherche et l'Enseignement en Neurosciences criteria were used in the diagnosis of $\mathrm{VaD} .{ }^{[24]}$ The severity of dementia was rated by the Clinical Dementia Rating (CDR) Scale. ${ }^{[25]}$

Body weight and height were measured without shoes and with light clothing. The body mass index was calculated by dividing the body weight by square of height $\left(\mathrm{kg} / \mathrm{m}^{2}\right)$. The World Health Organization T-score definitions were used to interpret DXA results as follows: T-score >-1: normal, $\leq-1$ : LBM, $\leq-2.5$ : osteoporosis. ${ }^{[19]}$

\section{Statistical analysis}

Statistical analysis was performed using the IBM SPSS version 23.0 software (IBM Corp., Armonk, NY, USA). Descriptive data were expressed in mean \pm standard deviation (SD), median (min-max) or number and frequency. The Shapiro-Wilk test was used to test normality. Differences between dementia and control groups were determined either by Student's 
t-test, Mann-Whitney $U$ test, or chi-square $\left(\chi^{2}\right)$ test depending upon the type and distribution of variables. The Spearman rank correlation coefficients were calculated to test simple correlations. The $\chi^{2}$, one-way analysis of variance (ANOVA) test or Kruskal-Wallis test was used to examine significant differences between dementia subtypes. Analysis of covariance (ANCOVA) was used to evaluate the adjusted differences of BMD values in the dementia and control groups, with age and sex as covariates which are known to be significantly associated with reduced bone mass and osteoporosis. ${ }^{[26]}$ Continuous variables with a positively skewed distribution were log transformed. Confidence intervals (Cis) for osteoporosis and LBM prevalence were provided by a binomial single-sample proportions test using the exact method of Clopper and Pearson. Age and sex-adjusted differences in the prevalence of osteoporosis and LBM in dementia and control groups, as well as the adjusted prevalence ratio (PR) (taking the control group as the standard) were calculated using log-binomial logistic regression analysis. A $p$ value of $<0.05$ was considered statistically significant.

\section{RESULTS}

Of a total of 363 participants, most (69.1\%) were educated less than five years. Hypertension (76.6\%) and decreased glomerular filtration rate (GFR) (60.1\%) were the most common comorbidities. About onefifth of the total study population had CVD (either coronary heart disease or stroke).

The dementia group $(n=93)$ and the control group $(n=270)$ were similar for age and sex. Table 1 shows the general characteristics of the patients and controls. The patients with dementia were more likely to have a stroke, CVD, lower GFR, folate deficiency, polypharmacy, or depression, and a lower education status. There was no significant difference

\section{TABLE 1}

Baseline demographic and clinical characteristics and cognitive findings of study population

\begin{tabular}{|c|c|c|c|c|c|c|c|c|c|c|}
\hline & \multicolumn{3}{|c|}{ Total $(n=363)$} & \multicolumn{3}{|c|}{ Dementia $(n=93)$} & \multicolumn{3}{|c|}{ No dementia $(n=270)$} & \multirow[b]{2}{*}{$p$} \\
\hline & $\mathrm{n}$ & $\%$ & Mean \pm SD & $\mathrm{n}$ & $\%$ & Mean \pm SD & $\mathrm{n}$ & $\%$ & Mean \pm SD & \\
\hline Age (year) & & & $78.4 \pm 5.4$ & & & $78.4 \pm 5.1$ & & & $78.7 \pm 6.0$ & 0.614 \\
\hline $65-74$ & 92 & 25.3 & & 23 & 24.7 & & 69 & 25.6 & & 0.875 \\
\hline $75-84$ & 222 & 61.2 & & 56 & 60.2 & & 166 & 61.5 & & 0.829 \\
\hline$>84$ & 49 & 13.5 & & 14 & 15.1 & & 35 & 13 & & 0.611 \\
\hline \multicolumn{11}{|l|}{ Gender } \\
\hline Female & 227 & 62.5 & & 58 & 62.4 & & 169 & 62.6 & & 0.969 \\
\hline Lower education $^{\mathrm{a}}$ & 251 & 69.1 & & 76 & 81.7 & & 175 & 64.8 & & 0.002 \\
\hline Past/current smoking & 95 & 26.2 & & 28 & 30.1 & & 67 & 24.8 & & 0.317 \\
\hline Coronary heart disease & 59 & 16.3 & & 14 & 15.1 & & 45 & 16.7 & & 0.716 \\
\hline Stroke & 25 & 6.9 & & 15 & 16.1 & & 10 & 3.7 & & $<0.001$ \\
\hline Cardiovascular disease & 78 & 21.5 & & 25 & 26.9 & & 53 & 19.6 & & 0.142 \\
\hline Diabetes mellitus & 74 & 20.4 & & 14 & 15.1 & & 60 & 22.2 & & 0.139 \\
\hline Hypertension & 278 & 76.6 & & 71 & 76.3 & & 207 & 76.7 & & 0.949 \\
\hline Hypercholesterolemia & 135 & 37.2 & & 32 & 34.4 & & 103 & 38.1 & & 0.520 \\
\hline GFR $<60 \mathrm{~mL} / \mathrm{min}$ & 211 & 60.1 & & 63 & 69.2 & & 148 & 56.9 & & 0.039 \\
\hline Anemia & 66 & 18.2 & & 18 & 19.4 & & 48 & 17.8 & & 0.745 \\
\hline Hypothyroidism & 40 & 11.3 & & 12 & 13 & & 28 & 10.7 & & 0.539 \\
\hline Vitamin B12 deficiency & 223 & 61.4 & & 56 & 60.2 & & 167 & 61.9 & & 0.780 \\
\hline Folate deficiency & 53 & 15.6 & & 25 & 29.4 & & 28 & 11 & & $<0.001$ \\
\hline Vitamin D deficiency & 96 & 43.8 & & 25 & 45.5 & & 71 & 43.3 & & 0.780 \\
\hline Polypharmacy & 185 & 51 & & 59 & 63.4 & & 126 & 46.7 & & 0.005 \\
\hline Body mass index & & & $29.5 \pm 5.5$ & & & $28.2 \pm 5.7$ & & & $30 \pm 5.3$ & 0.009 \\
\hline
\end{tabular}




\begin{tabular}{|c|c|c|c|c|c|c|c|c|c|}
\hline \multirow[b]{4}{*}{$\operatorname{BMD}\left(\mathrm{g} / \mathrm{cm}^{2}\right)$} & \multicolumn{6}{|c|}{$\begin{array}{l}\text { TABLE } 2 \\
\text { comparisons at three sites } \dagger\end{array}$} & \multirow{2}{*}{\multicolumn{3}{|c|}{ Difference: Dementia - Control }} \\
\hline & \multicolumn{2}{|c|}{ Unadjusted } & \multicolumn{4}{|c|}{ Adjusted ${ }^{*}$} & & & \\
\hline & $\begin{array}{l}\text { Dementia } \\
(n=93)\end{array}$ & $\begin{array}{l}\text { Control } \\
(n=270)\end{array}$ & Dementia & & Control & & \multicolumn{3}{|c|}{ Adjusted } \\
\hline & Mean \pm SD & Mean \pm SD & Mean \pm SE & $95 \% \mathrm{CI}$ & Mean $\pm S E$ & $95 \% \mathrm{CI}$ & Mean & $95 \% \mathrm{CI}$ & $p$ \\
\hline Lumbar & $889.7 \pm 147.3$ & $951.4 \pm 641.5$ & $890.0 \pm 57.9$ & $776.1-1004.0$ & $951.2 \pm 34.1$ & $884.3-1018.2$ & -61.2 & $-193.4-71.0$ & $0.308^{\star *}$ \\
\hline Total hip & $801.3 \pm 126.9$ & $855.4 \pm 156.2$ & $802.7 \pm 14.1$ & $775.0-830.3$ & $854.9 \pm 8.3$ & $838.7-871.2$ & -52.3 & $-84.3-20.2$ & 0.001 \\
\hline Femoral neck & $645.0 \pm 93.0$ & $701.5 \pm 130.7$ & $646.1 \pm 12.2$ & $622.1-670.0$ & $701.1 \pm 7.1$ & $687.1-715.1$ & -55.1 & $-82.8-27.3$ & $<0.001$ \\
\hline
\end{tabular}

in the other characteristics between the two groups (Table 1).

The mean time from the diagnosis of dementia was $22.3 \pm 26.3$ months. The ratio of patients with $\mathrm{AD}$, $\mathrm{VaD}$, and $\mathrm{AD}-\mathrm{VaD}$ were $52.7 \%(\mathrm{n}=49), 19.4 \%(\mathrm{n}=18)$, and $28.0 \%(n=26)$, respectively. The majority of the patients with dementia (72\%) had CDR-1 (mild), followed by CDR-2 (moderate, 24.7\%) and CDR-3 (severe, 3.2\%).

Unadjusted comparisons showed that the mean BMD values at the lumbar spine was similar in the participants with dementia and controls $(p=0.247)$. However, the mean BMD values at the total hip $(\mathrm{p}=0.001)$ and femoral neck $(\mathrm{p}<0.001)$ were significantly lower in the dementia group. Table 2 shows the adjusted comparisons of the mean BMD values at three sites. Controlling for age and sex, the differences in the mean BMD values at the total hip [F $(1,359): 10.26$, $\mathrm{p}=0.001]$ and femoral neck [F $(1,359): 15.21, \mathrm{p}<0.001]$ remained significant. The mean $\mathrm{BMD}$ values were more than $50 \mathrm{~g} / \mathrm{cm}^{2}$ lower in both the total hip and femoral neck sites in the dementia group, compared to healthy controls.
Table 3 shows a comparison of the prevalence of osteoporosis and LBM in both groups, and adjusted prevalence ratios taking the control group as the standard. Controlling for age and sex, based on a T-score of $\leq-2.5$ at any of three sites, the prevalence of osteoporosis was found to be higher in the dementia group, although not statistically significant [( $95 \% \mathrm{CI}$ : 0.93-2.50), $\mathrm{p}=0.097]$. However, based on a T-score of $\leq-2.5$ at the femoral neck, the adjusted prevalence of osteoporosis in the dementia group was significantly higher by 14 . Low bone mass, as defined by a T-score of $\leq-1.0$ at any of three sites, was significantly more frequent in the dementia group $(\mathrm{p}=0.009)$ after the adjustment. Also, there was a significant difference between dementia and control groups in terms of the LBM at the femoral neck $(\mathrm{p}<0.001)$.

The duration after diagnosis of dementia did not significantly correlate with BMD values at the lumbar spine $(\mathrm{r}=0.102, \mathrm{p}=0.329)$, total hip $(\mathrm{r}=-0.060, \mathrm{p}=0.570)$, and femoral neck $(\mathrm{r}=-0.007, \mathrm{p}=0.363)$. The BMD values were also similar in the demented patients with a median duration of eight months to a relatively newer diagnosis (lumbar spine, $p=0.728$; total hip, $p=0.680$; femoral neck, $\mathrm{p}=0.917$ ).

\begin{tabular}{|c|c|c|c|c|c|c|c|c|c|}
\hline & que & ostec & rosis and 1 & $\begin{array}{l}3 \\
\text { one }\end{array}$ & in st & populatio & \multirow[b]{3}{*}{ PR } & \multirow[b]{3}{*}{$95 \% \mathrm{CI}$} & \multirow[b]{3}{*}{$p^{*}$} \\
\hline & \multicolumn{3}{|c|}{ Dementia $(n=93)$} & \multicolumn{3}{|c|}{ No dementia $(\mathrm{n}=270)$} & & & \\
\hline & $\mathrm{n}$ & $\%$ & $95 \% \mathrm{CI}$ & $\mathrm{n}$ & $\%$ & $95 \% \mathrm{CI}$ & & & \\
\hline \multicolumn{10}{|l|}{ Osteoporosis } \\
\hline T-score $\leq-2.5$, any site & 38 & 40.9 & $30.8-51.5$ & 84 & 31.1 & $25.6-37.0$ & 1.16 & $0.97-1.39$ & 0.107 \\
\hline T-score $\leq-2.5$, femoral neck & 24 & 25.8 & $17.3-35.9$ & 43 & 15.9 & $11.8-20.8$ & 1.14 & $1.01-1.29$ & 0.040 \\
\hline \multicolumn{10}{|l|}{ Low bone mass } \\
\hline T-score $\leq-1.0$, any site & 89 & 95.7 & $89.4-98.8$ & 229 & 84.8 & $80.0-88.9$ & 3.49 & $1.29-9.44$ & 0.014 \\
\hline T-score $\leq-1.0$, femoral neck & 86 & 92.5 & $85.1-96.9$ & 191 & 70.7 & $70.0-64.9$ & 3.82 & $1.83-7.94$ & $<0.001$ \\
\hline
\end{tabular}




\begin{tabular}{|c|c|c|c|c|c|c|c|}
\hline \multicolumn{8}{|c|}{ Comparison of BMD values, frequency of oste } \\
\hline & \multicolumn{2}{|c|}{$\mathrm{AD}$} & \multicolumn{2}{|c|}{$\mathrm{VaD}$} & \multicolumn{2}{|c|}{$\mathrm{AD}-\mathrm{VaD}$} & \multirow[b]{2}{*}{$p$} \\
\hline & $\%$ & Mean \pm SD & $\%$ & Mean \pm SD & $\%$ & Mean \pm SD & \\
\hline \multicolumn{8}{|l|}{$\operatorname{BMD}\left(\mathrm{g} / \mathrm{cm}^{2}\right)$} \\
\hline Lumbar & & $891.9 \pm 156.9$ & & $913.1 \pm 152.6$ & & $869.3 \pm 126.2$ & 0.684 \\
\hline Total hip & & $780.6 \pm 132.8$ & & $846.2 \pm 135.3$ & & $809.3 \pm 102.7$ & 0.161 \\
\hline Femoral neck & & $628.1 \pm 98.5$ & & $682.9 \pm 143.5$ & & $650.5 \pm 88.8$ & 0.170 \\
\hline \multicolumn{8}{|c|}{ Frequency of osteoporosis } \\
\hline Femoral neck & 30.6 & & 22.2 & & 19.2 & & 0.522 \\
\hline \multicolumn{8}{|l|}{ Frequency of LBM } \\
\hline Femoral neck & 93.9 & & 83.3 & & 96.2 & & 0.246 \\
\hline
\end{tabular}

\begin{tabular}{|c|c|c|c|c|c|}
\hline \multicolumn{6}{|c|}{$\begin{array}{c}\text { TABLE } 5 \\
\text { Comparison of BMD values, frequency of osteoporosi } \\
\text { dementia severity }\end{array}$} \\
\hline & \multicolumn{2}{|c|}{ CDR-1 } & \multicolumn{2}{|c|}{ CDR-2/3 } & \multirow[b]{2}{*}{$p$} \\
\hline & $\%$ & Mean \pm SD & $\%$ & Mean \pm SD & \\
\hline \multicolumn{6}{|l|}{$\mathrm{BMD}\left(\mathrm{g} / \mathrm{cm}^{2}\right)$} \\
\hline Lumbar & & $893.9 \pm 157.7$ & & $878.9 \pm 118.5$ & 0.622 \\
\hline Total hip & & $808.0 \pm 126.7$ & & $784.1 \pm 128.1$ & 0.422 \\
\hline Femoral neck & & $648.4 \pm 106.1$ & & $636.2 \pm 110.9$ & 0.634 \\
\hline \multicolumn{6}{|c|}{ Frequency of osteoporosis } \\
\hline Femoral neck & 26.9 & & 23.1 & & 0.796 \\
\hline \multicolumn{6}{|l|}{ Frequency of LBM } \\
\hline Femoral neck & 92.5 & & 92.3 & & 1.000 \\
\hline
\end{tabular}

Among the dementia subtypes, the BMD measured at the lumbar $(\mathrm{p}=0.684)$, total hip $(\mathrm{p}=0.161)$, and femoral neck $(p=0.170)$ showed no significant difference (Table 4). In addition, the frequency of osteoporosis diagnosed by a T-score at the femoral neck was similar across the three dementia types $(\mathrm{p}=0.522)$ (Table 4). The LBM at the femoral neck was also similar $(\mathrm{p}=0.246)$ (Table 4).

There was no significant difference in the BMD values at the lumbar spine $(p=0.622)$, total hip $(\mathrm{p}=0.422)$, and femoral neck $(\mathrm{p}=0.634)$ between CDR-1 and CDR-2/3 patients (Table 5 ). In addition, based on a femoral neck T-score, CDR-1 patients had a similar osteoporosis $(\mathrm{p}=0.796)$ and LBM $(\mathrm{p}=1.000)$ ratios, compared to those with CDR-2/3 (Table 5).

Among cognitively intact individuals, controlling for age, the BMD values at the femoral neck of women was $88.22 \mathrm{~g} / \mathrm{cm}^{2}$ lower compared to men [F $(1,267)$ : 29.24, $\mathrm{p}<0.001$ (log transformed)]. No sex difference was observed in the femoral neck mean BMD values in the patients with dementia [F $(1,90): 3.72, \mathrm{p}=0.057]$.

Age-adjusted difference in the osteoporosis $(\mathrm{p}=0.906)$ and LBM $(\mathrm{p}=0.254)$ prevalence according to the femoral neck BMD values were not found to be significant between women and men.

\section{DISCUSSION}

In the present study, we compared older adults having a diagnosis of dementia with cognitively healthy controls and found that the demented patients had a relatively lower total hip and femoral neck BMD, and a higher proportion of osteoporosis and LBM. The most significant difference in the BMD values appeared at the femoral neck, which is the most recommended site 
for the osteoporosis diagnosis. ${ }^{[27]}$ On the other hand, we found no significant difference in BMD values and the prevalence of osteoporosis at the lumbar spine in the patients with dementia. Also, those with $\mathrm{AD}, \mathrm{VaD}$, and $\mathrm{AD}-\mathrm{VaD}$ had similar BMD values, osteoporosis or LBM rates. Based on these findings, we suggest that older adults with dementia are more likely than others to develop weak bones and osteoporosis at the hip, which may explain the previously reported increase in the risk for fractures in these individuals. ${ }^{[5,28]}$ In this context, other than reducing the number of falls, maintaining and even improving the bone strength of older adults with dementia seem to be vital in the prevention of new fractures.

Several studies have examined the association between dementia and osteoporosis. In an earlier study, Johansson and Skoog ${ }^{[29]}$ found no significant difference in calcaneal BMD of 35 demented elderly aged over 85 years and matched controls, although more patients with dementia had osteoporosis and hip fractures. Later studies reported that patients with $\mathrm{AD}^{[12]}$ and even earliest $\mathrm{AD}^{[11]}$ had lower BMD values than cognitively healthy individuals. Moreover, the relative risk for hip fractures, but not vertebrae or wrist, was found to be higher among the dementia subtypes (i.e., $\mathrm{AD}$ and unspecified dementia). ${ }^{[28]}$ Another large-scale, prospective study with a six-year follow-up of individuals aged 60 to 75 years showed that, along with age, female sex, vitamin D deficiency, smoking, drinking and stroke, the presence of $\mathrm{AD}$ increased the risk for new osteoporosis. ${ }^{[30]}$ Of note, not all fractures occur due to reduced bone mass. ${ }^{[31]}$ However, our study indicates that, apart from the increased risk for osteoporosis and fractures that was shown previously, ${ }^{[28,32]}$ demented individuals have a reduced bone strength, particularly in the femoral neck.

Currently, there is a growing number of evidence showing that osteoporosis promotes the development of dementia. ${ }^{[33-42]}$ Several authors have reported that bone metabolism is altered in $\mathrm{MCI}$ and $\mathrm{AD}$ and individuals with a lower BMD have an increased risk for developing cognitive decline. ${ }^{[33-36]}$ Thus, the patients with dementia in the current study probably had an early-onset bone loss with a rapid progression before the occurrence of the symptoms of cognitive dysfunction. ${ }^{[37-39]}$ Moreover, patients having MCI and lower BMD values had a double risk for conversion to $\mathrm{AD}$, compared to the controls. ${ }^{[40]}$ In a recent cross-sectional study, along with several common comorbidities, osteoporosis was associated with $\mathrm{AD}$, supporting their co-existence. ${ }^{[41]}$ In a retrospective cohort analysis, the diagnosis of osteoporosis significantly increased the future risk for both dementia and $\mathrm{AD}^{[42]}$ Besides, a prospective, eight-year follow-up study showed that low femoral neck BMD values were associated with doubling of the risk for $\mathrm{AD}$, as well as all-cause dementia. ${ }^{[36]}$ Previously, patients with AD were also found to have BMD reduction before the initiation of symptoms. ${ }^{[1]]}$ In laboratory animals, the decrease of BMD occurred earlier than overt degeneration in a tau-based AD model. ${ }^{[35]}$ Furthermore, an evidence of concurrent impairments in bone remodeling and osteogenic gene signaling linked to both bone loss and neuropathology in the brain of AD-induced animals was recently reported. ${ }^{[34]}$ Thus, dementia and osteoporosis have a prodromal period, while the latest findings suggest that bone loss accelerates in the presence of neurodegeneration. ${ }^{[43]}$ In line with this finding, several authors have suggested that osteoporosis may be considered as an early risk factor for dementia. ${ }^{[42]}$

Similar to dementia, both osteoporosis and fragility fractures are more frequent among women. ${ }^{[19,27]}$ In a previous study, female sex was shown to be a predictor of hip fractures in patients with dementia. ${ }^{[29]}$ However, in later studies, an increased risk for BMD reduction and fractures in the early $\mathrm{AD}$ or established dementia were not found to be associated with traditional risk factors such as age, sex, smoking or selected comorbidities. ${ }^{[11,28,32]}$ Also, additional modifiers such as physical activity, frailty, overall cognitive level, depression, genetic make-up and use of bone affecting medications showed no interaction with the decreased BMD in early AD. ${ }^{[1]}$ Consistent with these results, there was no sex effect on BMD, osteoporosis, or LBM in our patients with dementia, compared to the control group. Such supportive evidence was obtained in previous studies showing no sex difference in the risk for hip fractures in demented individuals and comparable odds of new dementia in women and men diagnosed with

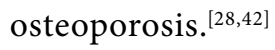

Cardiovascular disease commonly coexists with dementia, including $\mathrm{AD}^{[15,16]}$ Of note, available evidence suggests that osteoporosis is associated with CVD and stroke patients may have an even higher risk. ${ }^{[1718]}$ Therefore, we assumed that $\mathrm{VaD}$ and $\mathrm{AD}-\mathrm{VaD}$ patients in our study may have had lower BMD values, more osteoporosis or LBM; however, our analyses were consistent with no difference in this regard; 
even numerically lower numbers were seen in $\mathrm{VaD}$ and $\mathrm{AD}-\mathrm{VaD}$ patients. These findings were consistent with previous studies reporting similar rates of reduced BMD and fracture risk in different types of dementia. ${ }^{[28,36,42]}$ Thus, compared to other types of dementia, additional factors may be involved in the mechanism of reduced bone mass in patients with $\mathrm{AD}$.

The degree of bone loss or the frequency of osteoporosis across stages of dementia is almost unknown. A study conducted among nursing home residents found no significant correlation between dementia severity and fractures. ${ }^{[5]}$ Similarly, our study showed that BMD or osteoporosis frequency did not significantly differ in terms of dementia severity in the patient group which mainly consisted of those in CDR-1 and CDR-2 stages. This finding can be attributed to the fact that BMD reduction or osteoporosis started very early and that they were already at an advanced stage at the time of study participation.

Nonetheless, this study has several limitations. First, the cross-sectional design reduces our ability to draw causal relationships between dementia and BMD or osteoporosis. Second, we were unable to document falls and fractures due to missing data primarily in individuals without dementia having a normal DXA. As a fragility fracture is also diagnostic for osteoporosis, ${ }^{[19,27]}$ the inclusion of fracture data could have improved the accuracy of our results. Third, past or current medical treatments for osteoporosis were missing in our data; however, we recently reported that even non-demented older adults had significant recall errors in correctly reporting a previous osteoporosis diagnosis. ${ }^{[4]}$ In addition, our dementia sample included only the outpatients, limiting the generalizability of the results for advanced dementia or nursing home residents. Finally, due to the lower number of patients in the dementia subgroups, further studies are necessary to identify the level of risk attributable to $\mathrm{VaD}$ and $\mathrm{AD}-\mathrm{VaD}$ for $\mathrm{BMD}$ reduction and osteoporosis.

In conclusion, irrespective of the type, severity, and duration of the disease, the patients with dementia had reduced hip BMD, increased frequency of osteoporosis, and overall LBM compared to cognitively normal individuals. Unlike most other studies in the literature, we examined the relation of osteoporosis with all types of dementia, not only with $\mathrm{AD}$. Compared to controls, we found that female sex had no effect on the BMD or osteoporosis frequency in older adults with dementia. Thus, our study findings support the notion that reduced bone mass is one of the prevalent comorbidities in patients with dementia and, hence, implementing preventive measures is critical to prevent fractures in this population with a high risk for fractures.

\section{Declaration of conflicting interests}

The authors declared no conflicts of interest with respect to the authorship and/or publication of this article.

\section{Funding}

The authors received no financial support for the research and/or authorship of this article.

\section{REFERENCES}

1. Cauley JA, Thompson DE, Ensrud KC, Scott JC, Black D. Risk of mortality following clinical fractures. Osteoporos Int 2000;11:556-61.

2. Wright NC, Looker AC, Saag KG, Curtis JR, Delzell ES, Randall S, et al. The recent prevalence of osteoporosis and low bone mass in the United States based on bone mineral density at the femoral neck or lumbar spine. J Bone Miner Res 2014;29:2520-6.

3. Burton E, Cavalheri V, Adams R, Browne CO, BoverySpencer P, Fenton AM, et al. Effectiveness of exercise programs to reduce falls in older people with dementia living in the community: a systematic review and metaanalysis. Clin Interv Aging 2015;10:421-34.

4. Allan LM, Ballard CG, Rowan EN, Kenny RA. Incidence and prediction of falls in dementia: a prospective study in older people. PLoS One 2009;4:e5521.

5. Buchner DM, Larson EB. Falls and fractures in patients with Alzheimer-type dementia. JAMA 1987;257:1492-5.

6. Neu SC, Pa J, Kukull W, Beekly D, Kuzma A, Gangadharan P, et al. Apolipoprotein E Genotype and Sex Risk Factors for Alzheimer Disease: A Meta-analysis. JAMA Neurol 2017;74:1178-89.

7. Cizza G, Primma S, Csako G. Depression as a risk factor for osteoporosis. Trends Endocrinol Metab 2009;20:367-73.

8. Li G, Wang LY, Shofer JB, Thompson ML, Peskind ER, McCormick W, et al. Temporal relationship between depression and dementia: findings from a large community-based 15-year follow-up study. Arch Gen Psychiatry 2011;68:970-7.

9. Qizilbash N, Gregson J, Johnson ME, Pearce N, Douglas I, Wing K, et al. BMI and risk of dementia in two million people over two decades: a retrospective cohort study. Lancet Diabetes Endocrinol 2015;3:431-6.

10. Compston JE, Flahive J, Hosmer DW, Watts NB, Siris ES, Silverman S, et al. Relationship of weight, height, and body mass index with fracture risk at different sites in postmenopausal women: the Global Longitudinal study of Osteoporosis in Women (GLOW). J Bone Miner Res 2014;29:487-93.

11. Loskutova N, Honea RA, Vidoni ED, Brooks WM, Burns JM. Bone density and brain atrophy in early Alzheimer's disease. J Alzheimers Dis 2009;18:777-85.

12. Sato Y, Honda Y, Hayashida N, Iwamoto J, Kanoko T, Satoh K. RETRACTED: Vitamin K deficiency and osteopenia in elderly women with Alzheimer's disease. Arch Phys Med Rehabil 2005;86:576-81. 
13. Weller I, Schatzker J. Hip fractures and Alzheimer's disease in elderly institutionalized Canadians. Ann Epidemiol 2004;14:319-24.

14. Lv XL, Zhang, J, Gao WY, Xing WM, Yang ZX, Yue YX, et al. Association between Osteoporosis, Bone Mineral Density Levels and Alzheimer's Disease: A Systematic Review and Meta-analysis. International Journal of Gerontology 2018.

15. Tasci I, Safer U, Naharci MI, Gezer M, Demir O, Bozoglu E, et al. Undetected Peripheral Arterial Disease Among Older Adults With Alzheimer's Disease and Other Dementias. Am J Alzheimers Dis Other Demen 2018;33:5-11.

16. Newman AB, Fitzpatrick AL, Lopez O, Jackson S, Lyketsos C, Jagust W, et al. Dementia and Alzheimer's disease incidence in relationship to cardiovascular disease in the Cardiovascular Health Study cohort. J Am Geriatr Soc 2005;53:1101-7.

17. Farhat GN, Cauley JA. The link between osteoporosis and cardiovascular disease. Clin Cases Miner Bone Metab 2008;5:19-34.

18. Pouwels S, Lalmohamed A, Leufkens B, de Boer A, Cooper C, van Staa T, et al. Risk of hip/femur fracture after stroke: a population-based case-control study. Stroke 2009;40:3281-5.

19. Cosman F, de Beur SJ, LeBoff MS, Lewiecki EM, Tanner B, Randall S, et al. Clinician's Guide to Prevention and Treatment of Osteoporosis. Osteoporos Int 2014;25:2359-81.

20. Folstein MF, Folstein SE, McHugh PR. "Mini-mental state". A practical method for grading the cognitive state of patients for the clinician. J Psychiatr Res 1975;12:189-98.

21. Tombaugh TN, McIntyre NJ. The mini-mental state examination: a comprehensive review. J Am Geriatr Soc 1992;40:922-35.

22. Diagnostic and statistical manual of mental disorders (DSM-5). 5th ed. Washington: American Psychiatric Association; 2013.

23. McKhann G, Drachman D, Folstein M, Katzman R, Price D, Stadlan EM. Clinical diagnosis of Alzheimer's disease: report of the NINCDS-ADRDA Work Group under the auspices of Department of Health and Human Services Task Force on Alzheimer's Disease. Neurology 1984;34:939-44.

24. Gold G, Giannakopoulos P, Montes-Paixao Júnior C, Herrmann FR, Mulligan R, Michel JP, et al. Sensitivity and specificity of newly proposed clinical criteria for possible vascular dementia. Neurology 1997;49:690-4.

25. Hughes CP, Berg L, Danziger WL, Coben LA, Martin RL. A new clinical scale for the staging of dementia. Br J Psychiatry 1982;140:566-72.

26. Kanis JA, Borgstrom F, De Laet C, Johansson H, Johnell O, Jonsson B, et al. Assessment of fracture risk. Osteoporos Int 2005;16:581-9.

27. Qaseem A, Forciea MA, McLean RM, Denberg TD; Clinical Guidelines Committee of the American College of Physicians. Treatment of Low Bone Density or Osteoporosis to Prevent Fractures in Men and Women: A Clinical Practice Guideline Update From the American College of Physicians. Ann Intern Med 2017;166:818-39.
28. Wang HK, Hung CM, Lin SH, Tai YC, Lu K, Liliang PC, et al. Increased risk of hip fractures in patients with dementia: a nationwide population-based study. BMC Neurol 2014;14:175.

29. Johansson C, Skoog I. A population-based study on the association between dementia and hip fractures in 85-year olds. Aging (Milano) 1996;8:189-96.

30. Liu D, Zhou H, Tao Y, Tan J, Chen L, Huang H, et al. Alzheimer's Disease is Associated with Increased Risk of Osteoporosis: The Chongqing Aging Study. Curr Alzheimer Res 2016;13:1165-72.

31. Stone KL, Seeley DG, Lui LY, Cauley JA, Ensrud K, Browner WS, et al. BMD at multiple sites and risk of fracture of multiple types: long-term results from the Study of Osteoporotic Fractures. J Bone Miner Res 2003;18:1947-54.

32. Zhou R, Deng J, Zhang M, Zhou HD, Wang YJ. Association between bone mineral density and the risk of Alzheimer's disease. J Alzheimers Dis 2011;24:101-8.

33. Luckhaus C, Mahabadi B, Grass-Kapanke B, Jänner $\mathrm{M}$, Willenberg $\mathrm{H}$, Jäger $\mathrm{M}$, et al. Blood biomarkers of osteoporosis in mild cognitive impairment and Alzheimer's disease. J Neural Transm (Vienna) 2009;116:905-11.

34. Dengler-Crish CM, Ball HC, Lin L, Novak KM, Cooper LN. Evidence of $\mathrm{Wnt} / \beta$-catenin alterations in brain and bone of a tauopathy mouse model of Alzheimer's disease. Neurobiol Aging 2018;67:148-58.

35. Dengler-Crish CM, Smith MA, Wilson GN. Early Evidence of Low Bone Density and Decreased Serotonergic Synthesis in the Dorsal Raphe of a Tauopathy Model of Alzheimer's Disease. J Alzheimers Dis 2017;55:1605-19.

36. Tan ZS, Seshadri S, Beiser A, Zhang Y, Felson D, Hannan $\mathrm{MT}$, et al. Bone mineral density and the risk of Alzheimer disease. Arch Neurol 2005;62:107-11.

37. Lui LY, Stone K, Cauley JA, Hillier T, Yaffe K. Bone loss predicts subsequent cognitive decline in older women: the study of osteoporotic fractures. J Am Geriatr Soc 2003;51:38-43.

38. Yaffe K, Browner W, Cauley J, Launer L, Harris T. Association between bone mineral density and cognitive decline in older women. J Am Geriatr Soc 1999;47:1176-82.

39. Laudisio A, Fontana DO, Rivera C, Ruggiero C, Bandinelli S, Gemma A, et al. Bone Mineral Density and Cognitive Decline in Elderly Women: Results from the InCHIANTI Study. Calcif Tissue Int 2016;98:479-88.

40. Zhou R, Zhou H, Rui L, Xu J. Bone loss and osteoporosis are associated with conversion from mild cognitive impairment to Alzheimer's disease. Curr Alzheimer Res 2014;11:706-13.

41. Wang JH, Wu YJ, Tee BL, Lo RY. Medical Comorbidity in Alzheimer's Disease: A Nested Case-Control Study. J Alzheimers Dis 2018;63:773-81.

42. Chang KH, Chung CJ, Lin CL, Sung FC, Wu TN, Kao CH. Increased risk of dementia in patients with osteoporosis: a population-based retrospective cohort analysis. Age (Dordr) 2014;36:967-75.

43. Roos PM. Osteoporosis in neurodegeneration. J Trace Elem Med Biol 2014;28:418-21.

44. Tasci I, Basgoz BB, Cintosun U, Safer U, Naharci MI. Age at First Osteoporosis Screening Among Older Women and Men: Is Bone Mineral Density Measurement Ordered Timely? Endocr Metab Immune Disord Drug Targets 2019;19:534-40. 